\title{
Differences in Rate of Complete Excision of Basal Cell Carcinoma by Dermatologists, Plastic Surgeons and General Practitioners: A Large Cross-Sectional Study
}

\author{
Kirtie Ramdas ${ }^{\mathrm{a}}$ Charlotte van Lee ${ }^{\mathrm{a}}$ Samuel Beck ${ }^{\mathrm{b}}$ Patrick Bindels ${ }^{\mathrm{c}}$ \\ Vincent Noordhoek Hegt ${ }^{d}$ Luba Pardo ${ }^{a}$ Sarah Versnel ${ }^{\mathrm{e}}$ Tamar Nijsten $^{\mathrm{a}}$ \\ Renate van den Bos $^{\mathrm{a}}$ \\ a Department of Dermatology, Erasmus Medical Center Cancer Institute, Rotterdam, The Netherlands;

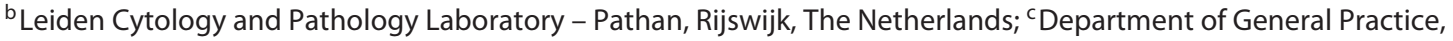 \\ Erasmus Medical Center Cancer Institute, Rotterdam, The Netherlands; ${ }^{d}$ Department of Pathology, Erasmus Medical

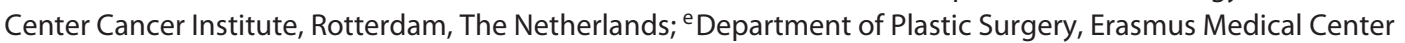 \\ Cancer Institute, Rotterdam, The Netherlands
}

\section{Keywords}

Margins of excision - Basal cell carcinoma - Medicine Physicians - Quality of health care - Comparative study . Surgery - General practitioners - Dermatologists · Plastic surgeons

\section{Abstract \\ Background: Due to the increasing incidence of basal cell carcinoma (BCC) and rising health care costs, health care in- surance companies seek ways to shift skin surgery for BCC from secondary to primary care. Objectives: To study the dif- ferences in complete excision of BCC by general practitio- ners (GPs), dermatologists, and plastic surgeons. Methods: A retrospective cross-sectional study of pathology records of 2,986 standard excisions of primary BCCs performed by a GP, dermatologist, or plastic surgeon in the area of Southwest}

\begin{tabular}{ll}
\hline KARGER & $\begin{array}{l}\text { (c) } 2018 \text { The Author(s) } \\
\text { Published by S. Karger AG, Basel }\end{array}$ \\
E-Mail karger@karger.com & This article is licensed under the Creative Commons Attribution- \\
www.karger.com/drm & $\begin{array}{l}\text { NonCommercial-NoDerivatives 4.0 International License (CC BY- } \\
\text { NC-ND) (http://www.karger.com/Services/OpenAccessLicense). } \\
\text { Usage and distribution for commercial purposes as well as any dis- } \\
\text { tribution of modified material requires written permission. }\end{array}$
\end{tabular}

Netherlands between 2008 and 2014. To compare the risk of an incomplete BCC excision between the specialties, the odds ratio (OR) was used adjusted for patient age, sex, tumor site, size, and histological subtype. Results: BCCs were completely excised by GPs in 70\%, which was lower than the $93 \%$ by dermatologists and $83 \%$ by plastic surgeons $(p<0.001)$. Compared to the dermatologist, BCCs which were excised by a GP were 6 times higher at risk of an incomplete excision (adjusted OR 6, 95\% Cl 5-8) and 2 times higher at risk when excised by a plastic surgeon (adjusted OR 2, 95\% Cl 2-3). Conclusion: BCCs were more often completely excised by dermatologists than by GPs and plastic surgeons. Dermatologists probably perform better because of their extensive training and high experience in BCC care. To minimize incomplete BCC excision, GPs should receive specific training before the shift of BCC care from secondary to primary care is justifiable.

(C) 2018 The Author(s)

Published by S. Karger AG, Basel

R.R. van den Bos

Burgemeester s' Jacobplein 51

NL-3015 CA Rotterdam (The Netherlands)

E-Mail r.vandenbos@erasmusmc.nl 


\section{Introduction}

Basal cell carcinoma (BCC) is the most common cancer in the Netherlands. According to the Netherlands Cancer Registry, the BCC incidence rate is about 40,000 per year with an increase of $5 \%$ each year [1]. In the Netherlands, patients initially visit a general practitioner (GP) for their skin lesions. The GPs decide whether to treat the patient themselves or to refer to a specialist. Although Dutch GPs are not specifically trained in skin tumor care (unlike counterparts in the UK and Australia), they do excise $27 \%$ of the benign skin tumors they encounter and $31 \%$ of the skin tumors they suspect to be malignant [2, 3]. If GPs refer a patient with a skin tumor, this is most often to a dermatologist or plastic surgeon, and less often to an ophthalmologist, general surgeon or ear-nose-andthroat specialist. In the Netherlands, until June 2017, a specific BCC guideline for GPs was lacking, while specialists could refer to their multidisciplinary conducted Dutch BCC guideline since 2002. Adherence to guidelines, however, might vary within and between specialists, which may result in different treatment choices and quality of care. According to the Dutch BCC guideline, the first choice of treatment for BCC is a standard excision, with a clinical tumor-free excision margin of $3 \mathrm{~mm}$ for nonaggressive BCC subtypes (i.e., nodular and superficial) $<2 \mathrm{~cm}$ and a $5-\mathrm{mm}$ margin for larger BCCs or BCCs with an aggressive histological subtype (i.e., infiltrative or micronodular) [4]. Incompletely excised BCCs need reexcision to prevent recurrence, as recurrent BCCs can be more aggressive and therefore more difficult to treat, leading to impaired functional and cosmetic outcome for patients and higher costs for society.

Health insurance companies and governments worldwide promote a shift of minor skin surgery from secondary to primary care in order to reduce health care costs [5-7]. Accordingly, the Dutch Collaborating Centre of the WHO promotes a shift of BCC care, even though it is unknown whether the quality of BCC care among GPs is sufficient compared to medical specialists. The quality of BCC care among GPs and medical specialists needs to be carefully assessed, as quality of care should not be compromised in order to reduce costs. One of the indicators for the quality of BCC care is the rate of completely excised BCCs. This retrospective cross-sectional study of pathology records compared the rate of completely excised BCCs between GPs, dermatologists, and plastic surgeons in the Netherlands.

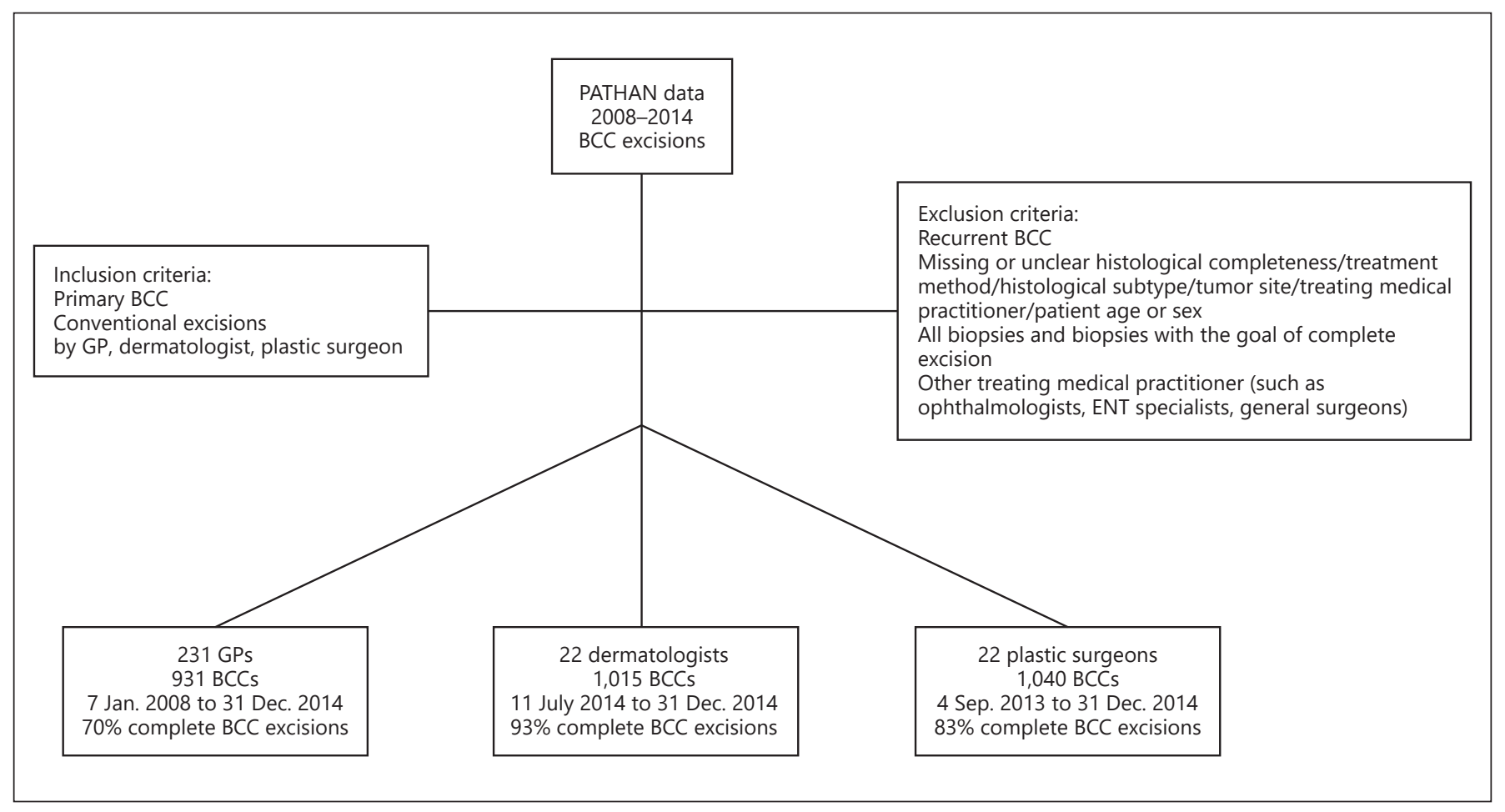

Fig. 1. Flowchart of Material and Methods.

Complete Excision of Basal Cell

Carcinoma by Different Specialties
Dermatology 2018;234:86-91

DOI: $10.1159 / 000490344$ 
Table 1. A comparison of patient characteristics and number of complete basal cell carcinoma excisions between specialties, with subdivisions per site and histopathological subtype

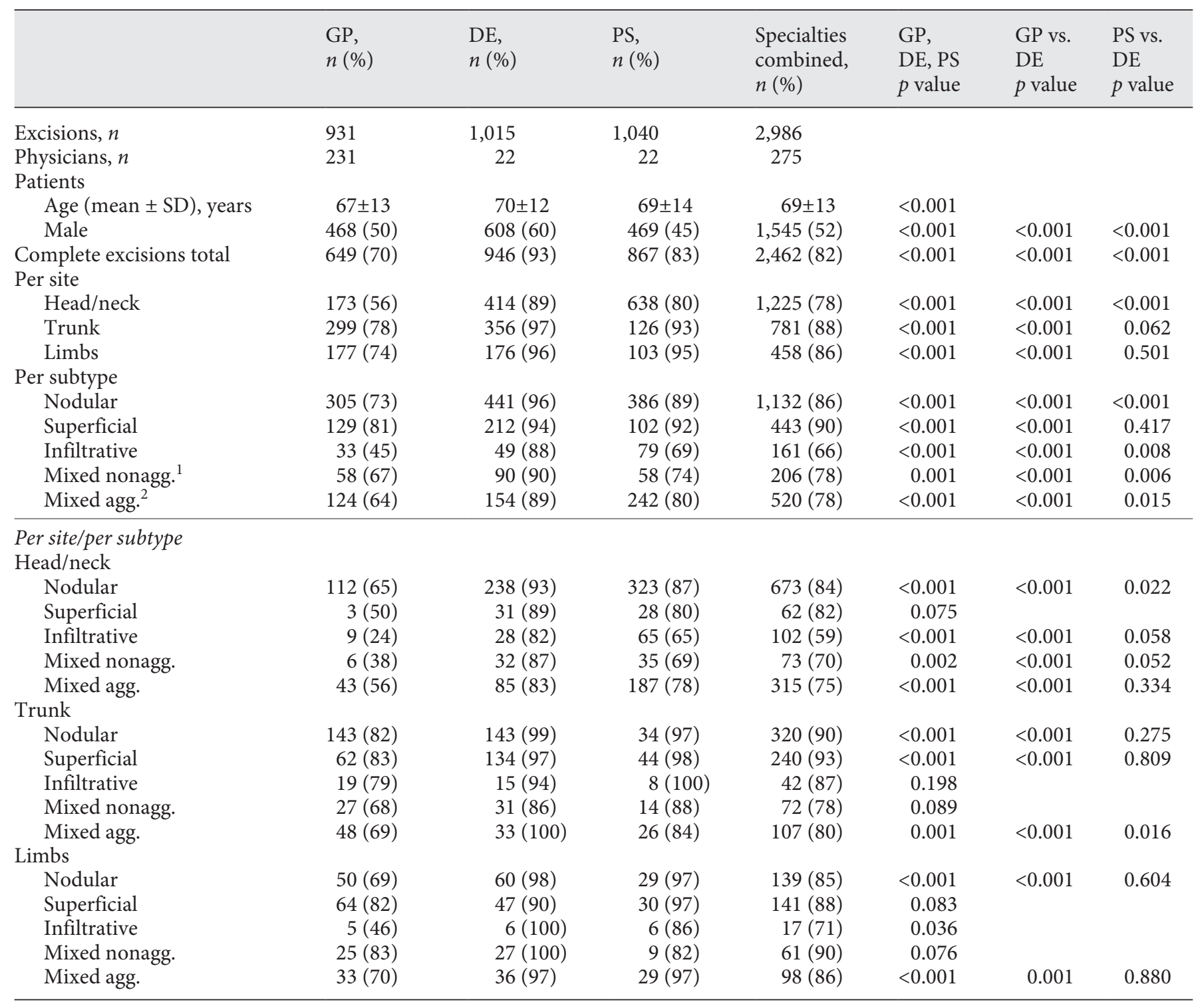

Percentages were rounded. GP, general practitioner; DE, dermatologist; PS, plastic surgeon; nonagg., nonaggressive; agg., aggressive. ${ }^{1}$ Mixed nonaggressive basal cell carcinomas were superficial with nodular type $(n=264) .{ }^{2}$ Mixed aggressive basal cell carcinomas $(n=668)$ were: superficial with infiltrative $(n=48)$, superficial with nodular and infiltrative $(n=67)$, nodular with infiltrative $(n=544)$, and infiltrative with micronodular type $(n=9)$.

\section{Materials and Methods}

For further details, see the online supplementary material (see www.karger.com/doi/10.1159/000490344 for all online suppl. material) (Fig. 1).

\section{Results}

In total 2,986 pathology records of BCC excisions were included. The patients' median age was 69 years ( $S D \pm 13$ years), and $52 \%$ were male. Of the 2,986 BCCs, 931 were excised by a GP $(n=231)$ in a period of 6 years, 1,015 by a dermatologist $(n=22)$ in a period of 6 months, and 
Table 2. Risk of incomplete basal cell carcinoma (BCC) excision between specialties, adjusted for tumor and patient characteristics

\begin{tabular}{|c|c|c|c|c|c|}
\hline \multirow[t]{2}{*}{ Category } & \multirow[t]{2}{*}{ Variable } & \multicolumn{2}{|c|}{ Univariable analysis } & \multicolumn{2}{|c|}{ Multivariable analysis } \\
\hline & & $\begin{array}{l}\text { OR }(95 \% \mathrm{CI}) \\
\text { for incomplete } \\
\text { BCC excision }\end{array}$ & $p$ value & $\begin{array}{l}\text { OR }(95 \% \mathrm{CI}) \\
\text { for incomplete } \\
\text { BCC excision }\end{array}$ & $p$ value \\
\hline \multirow[t]{3}{*}{ Specialty } & Dermatologist & ref. & & & \\
\hline & General practitioner & $6.0(4.5-7.9)$ & $<0.0001$ & $6.2(4.6-8.4)$ & $<0.0001$ \\
\hline & Plastic surgeon & $2.7(2.0-3.7)$ & $<0.0001$ & $2.0(1.5-2.7)$ & $<0.0001$ \\
\hline \multirow{10}{*}{$\begin{array}{l}\text { Tumor } \\
\text { characteristics }\end{array}$} & Trunk & ref. & & & \\
\hline & Head/neck & $2.1(1.7-2.7)$ & $<0.0001$ & $2.7(2.0-3.6)$ & $<0.0001$ \\
\hline & Limbs & $1.2(0.9-1.7)$ & 0.248 & $1.1(0.8-1.5)$ & 0.605 \\
\hline & $\leq 2.5 \mathrm{~cm}$ & Ref. & & & \\
\hline & $>2.5 \mathrm{~cm}$ & $0.3(0.2-0.4)$ & $<0.0001$ & $0.4(0.3-0.5)$ & $<0.0001$ \\
\hline & Nodular & Ref. & & & \\
\hline & Superficial & $0.7(0.5-1.0)$ & 0.055 & $1.3(0.9-1.9)$ & 0.146 \\
\hline & Infiltrative & $3.2(2.4-4.3)$ & $<0.0001$ & $3.4(2.4-4.7)$ & $<0.0001$ \\
\hline & Mixed nonaggressive ${ }^{1}$ & $1.7(1.3-2.4)$ & $<0.001$ & $2.6(1.8-3.7)$ & $<0.0001$ \\
\hline & Mixed aggressive $^{2}$ & $1.8(1.4-2.2)$ & $<0.0001$ & $2.0(1.6-2.6)$ & $<0.0001$ \\
\hline \multirow{3}{*}{$\begin{array}{l}\text { Patient } \\
\text { characteristics }\end{array}$} & Male & Ref. & & & \\
\hline & Female & $1.1(0.9-1.4)$ & 0.207 & $1.0(0.8-1.2)$ & 0.768 \\
\hline & Age (for a difference of 1 year) & $1.0(1.0-1.0)$ & 0.074 & $1.0(1.0-1.0)$ & 0.069 \\
\hline
\end{tabular}

Percentages were rounded. OR, odds ratio; CI, confidence interval; BCC, basal cell carcinoma. ${ }^{1}$ Mixed nonaggressive BCCs were superficial with nodular type $(n=264) .{ }^{2}$ Mixed aggressive BCCs $(n=668)$ were: superficial with infiltrative $(n=48)$, superficial with nodular and infiltrative $(n=67)$, nodular with infiltrative $(n=544)$, and infiltrative with micronodular type $(n=9)$.

1,040 by a plastic surgeon $(n=22)$ in a period of 15 months (Table 1).

Overall, BCCs were completely excised in $82 \%$ $(2,462 / 2,986)$ (Table 1). BCCs were completely excised by GPs in 70\% (649/931), which was lower than the $93 \%$ $(946 / 1,015)$ by dermatologists, and $83 \%(867 / 1,040)$ by plastic surgeons $(p<0.001)$. Compared to the dermatologist, BCCs which were excised by a GP were 6 times higher at risk of an incomplete excision (adjusted OR 6, 95\% CI 5-8) and 2 times higher at risk when excised by a plastic surgeon (adjusted OR 2, 95\% CI 2-3) $(p<0.0001)$ (Table 2). The risk of an incomplete excision was higher for small BCCs (adjusted OR 0.4, 95\% CI 0.3-0.5, $p<0.0001$ ). The risk of an incomplete $\mathrm{BCC}$ excision was not increased by patients' age or sex.

\section{BCCs of the Head and Neck}

BCCs of the head and neck were completely excised in $78 \%$, which was lower than the $88 \%$ of completely excised BCCs of the trunk and $86 \%$ of the limbs (Table $1)$. The risk of an incomplete excision was higher for
BCCs of the head and neck than for BCCs of the trunk and limbs (adjusted OR 3, 95\% CI 2-4) $(p<0.0001)$ (Table 2). BCCs of the head and neck were completely excised by GPs in $56 \%$, which was lower than the $89 \%$ for dermatologists and $80 \%$ for plastic surgeons (Table $1)$. For the complete excision of a BCC of the head and neck, dermatologists performed better than GPs and plastic surgeons $(p<0.001)$. When BCCs of the head and neck were subdivided per histological subtype, GPs still showed the lowest proportion of complete excisions when compared to the dermatologists $(p<0.001$ for each subtype), while differences between dermatologists and plastic surgeons were not significant $(p>$ 0.0125).

\section{BCCs with an Infiltrative or Mixed Histological Subtype}

Infiltrative BCCs were completely excised in $66 \%$, which was lower than the $86 \%$ of nodular, $90 \%$ of superficial, $78 \%$ of mixed nonaggressive, and $78 \%$ of mixed aggressive BCCs $(p<0.001)$ (Table 1$)$. 
The risk of an incomplete excision was higher for BCCs with the following histological subtypes: infiltrative (adjusted OR 3, 95\% CI 2-5), mixed nonaggressive (adjusted OR 3, 95\% CI 2-4), and mixed aggressive (adjusted OR 2, 95\% CI 2-3) $(p<0.0001)$. Infiltrative BCCs were completely excised by GPs in $45 \%$, which was lower than the $88 \%$ for dermatologists, and $69 \%$ for plastic surgeons. For the complete excision of an infiltrative BCC, dermatologists performed better than GPs and plastic surgeons $(p<0.0125)$. For both mixed nonaggressive and mixed aggressive subtypes, GPs had the lowest proportions of completely excised BCCs when compared to dermatologists and plastic surgeons. For the complete excision of mixed nonaggressive and mixed aggressive subtypes, dermatologists performed better than GPs $(p<0.001)$.

\section{Discussion}

This retrospective cross-sectional study of 2,986 pathology records from a Dutch regional laboratory, showed that primary BCCs were more often completely excised by a dermatologist $(93 \%)$ than by a GP $(70 \%)$ or plastic surgeon (83\%). Compared to the dermatologist, BCCs which were excised by a GP were 6 times higher at risk of an incomplete excision (adjusted OR 6, 95\% CI 5-8) and 2 times higher at risk when excised by a plastic surgeon (adjusted OR 2, 95\% CI 2-3) $(p<0.0001)$.

Previous studies found similar proportions of complete BCC excisions; however, these studies lack a sample size calculation, subgroup analyses per tumor site and histological subtype, and logistic regressions [8-11]. Dermatologists probably excise BCC more often complete than GPs and plastic surgeons because dermatologists are specifically trained in BCC care during their 5 years of specialization, and dermatologists are more experienced in BCC care due to the high case load in their daily practice. This might result in better clinical skills among dermatologists in recognizing skin lesions as suspected for $\mathrm{BCC}$, and in demarcating the tumor preoperatively. Both skills contribute to the success of a complete BCC excision.

The risk of an incomplete excision was found higher for BCCs of the head and neck than for BCCs of the trunk and limbs (adjusted OR 3, 95\% CI 2-4) $(p<0.0001)$, irrespectively of the specialist who performed the excision. First, this could be explained because BCCs of the $\mathrm{H}$ zone are known to grow more aggressively. Second, physicians might narrow their excision margins for BCCs of the head and neck to preserve functional and cosmetic outcome.
The risk of an incomplete excision was found to be higher for BCCs with an infiltrative or mixed histological subtype than for nodular or superficial BCCs. Smeets et al. [12] showed that excisions with a clinical tumor-free margin of $3 \mathrm{~mm}$ for primary facial BCCs with an infiltrative histological subtype were more often incomplete $(25 \%)$ than other subtypes $(12 \%, p<0.05)$. These findings suggest that preoperative histological subtype determination might be useful to indicate when wider clinical tumor-free excision margins are needed. Although in 1 out of 6 BCCs the most aggressive growth pattern is missed by the preoperative biopsy (i.e., sampling error), a biopsy was shown to be more sensitive and more specific than the clinical diagnosis on the histological subtype $[13,14]$.

Remarkably, the risk of an incomplete excision was found higher for small BCCs (i.e., $\leq 2 \mathrm{~cm}$ ). The clinical demarcation of a small BCC might be more difficult due to scar formation after a preoperative biopsy.

Strengths of this study are: the comparative design, the large sample size and analysis per tumor site, and histological subtype. This study was limited to a retrospective design which implicated selection bias between the specialties. Therefore, risk of an incomplete BCC excision between the specialties was adjusted for BCC site, specimen size, histological subtype, patients' age, and sex. But due to missing data, BCC localization in the $\mathrm{H}$ zone and exact clinical tumor size could not be specified. Also, it was unknown whether the BCC diagnosis was confirmed histologically prior to the excision and which excision margins were used. The real proportion of completely excised BCCs was overestimated in all groups due to missing tumor on the histological margins by applying the breadloaf technique.

In conclusion, this study shows that primary BCCs were more often completely excised by dermatologists than by GPs and plastic surgeons. Among GPs, complete excisions were specifically low for BCCs of the head and neck and BCCs with an infiltrative subtype. Dermatologists probably perform better because of their extensive training and high experience in BCC care. Before a shift of BCC care from secondary to primary care, there is a strong need for an integrated care pathway, including adequate training for GPs.

\section{Key Message}

Basal cell carcinomas are more often completely excised by dermatologists than by general practitioners or plastic surgeons.
Ramdas et al. 


\section{Statement of Ethics}

The study was conducted and reported according to the STROBE guidelines for cross-sectional studies. The Medical Ethical Committee of the Erasmus MC Rotterdam approved the study protocol (reference No. NL52923.078.15).

\section{Disclosure Statement}

The authors have no conflicts of interest to disclose.

\section{Funding Sources}

This study has received funding from the Dutch health insurance company Zilveren Kruis Zorgverzekeringen NV in order to investigate current skin cancer care in the Netherlands. The funder had no role in the study design, data collection and analysis, decision to publish, or preparation of the manuscript.

\section{References}

1 Flohil SC, Seubring I, van Rossum MM, Coebergh JW, de Vries E, Nijsten T: Trends in basal cell carcinoma incidence rates: a 37-year Dutch observational study. J Invest Dermatol 2013;133:913-918.

2 Van Dijk CE, Verheij RA, Spreeuwenberg P, Groenewegen PP, de Bakker DH: Minor surgery in general practice and effects on referrals to hospital care: observational study. BMC Health Serv Res 2011;11:12.

3 Koelink CJ, Kollen BJ, Groenhof F, van der Meer K, van der Heide WK: Skin lesions suspected of malignancy: an increasing burden on general practice. BMC Fam Pract 2014;15: 29.

4 Kelleners-Smeets NMJ; for the Dutch Society for Dermatology and Venereology: Multidisciplinary evidence-based guideline basal cell carcinoma, version 16-10-2015, pp 1-20.

5 Pil L, Hoorens I, Vossaert K, Kruse V, Tromme I, Speybroeck N, Annemans L, Brochez L: Cost-effectiveness and budget effect analysis of a population-based skin cancer screening. JAMA Dermatol 2017;153:147-153.
6 De Jong J, Korevaar J, Kroneman M, van Dijk C, Bouwhuis S, de Bakker D: Substitutiepotentieel tussen eerste - en tweedelijns zorg. Utrecht, NIVEL, 2016.

7 Van Dijk CE, Korevaar JC, de Jong JD, Koopmans B, van Dijk M, de Bakker DH: Kennisvraag ruimte voor substitutie? Verschuivingen van tweedelijns - naar eerstelijnszorg. Utrecht, NIVEL, 2013.

8 Murchie P, Delaney EK, Thompson WD, Lee AJ: Excising basal cell carcinomas: comparing the performance of general practitioners, hospital skin specialists and other hospital specialists. Clin Exp Dermatol 2008;33:565-571.

9 Haw WY, Rakvit P, Fraser SJ, Affleck AG, Holme SA: Skin cancer excision performance in Scottish primary and secondary care: a retrospective analysis. Br J Gen Pract 2014; 64:e465-e470.

10 Bassas P, Hilari H, Bodet D, Serra M, Kennedy FE, Garcia-Patos V: Evaluation of surgical margins in basal cell carcinoma by surgical specialty. Actas Dermosifiliogr 2013;104: 133-140.
11 Goulding JM, Levine S, Blizard RA, Deroide F, Swale VJ: Dermatological surgery: a comparison of activity and outcomes in primary and secondary care. Br J Dermatol 2009;161: 110-114.

12 Smeets NWJ, Krekels GAM, Ostertag JU, Essers BAB, Dirksen CD, Nieman FHM, Neumann HAM: Surgical excision vs Mohs' micrographic surgery for basal cell carcinoma of the face: randomized controlled trial. Lancet 2004;364:1766-1772.

13 Roozeboom MH, Mosterd K, Winnepenninckx VJL, Nelemans PJ, Kelleners-Smeets NWJ: Agreement between histological subtype on punch biopsy and surgical excision in primary basal cell carcinoma. J Eur Acad Dermatol Venereol 2013;27:894-898.

14 Roozeboom MH, Kreukels H, Nelemans PJ, Mosterd K, Winnepenninckx VJL, Hamid MAA, de Haas ERM, Kelleners-Smeets NWJ: Subtyping basal cell carcinoma by clinical diagnosis versus punch biopsy. Acta Derm Venereol 2015;95:996-998. 